\title{
One case of choriocarcinoma sellar region metastasis and literature review
}

\author{
Jin Sun and Yanlin Huang ${ }^{*}$
}

\begin{abstract}
Background: Chorionic carcinoma is a highly malignant gynecological tumor, frequently originating from trophoblastic cells in the uterus after fertilization. Early erosion releases cancerous cells into the circulation to invade surrounding organs without primary symptoms and signs.

Methods: One case of choriocarcinoma sellar region metastasis was analyzed, utilizing clinical data, MRI and pathological examinations, and clinical characteristics were summarized.

Results: Choriocarcinoma sellar region metastasis is easily misdiagnosed. We examined the literature and original resources to summarize the clinical characteristics of choriocarcinoma sellar region metastasis and discuss available therapies.

Conclusion: This case study of a metastasis of choriocarcinoma to the sellar region provides important new data on the incidence and pathology of this rare disease.
\end{abstract}

Keywords: Choriocarcinoma, Sellar region, Brain metastasis, Literature review

\section{Background}

Chorionic carcinoma is a highly malignant gynecological tumor, frequently originating from trophoblastic cells in the uterus after fertilization. Early erosion releases cancerous cells into the circulation to invade surrounding organs without primary symptoms and signs [1]. In the event of late brain metastases when disseminated tumor cells enter cerebrospinal fluid, few patients survive more than a year. Primary chorionic carcinoma is associated with lung metastasis in about one-third of cases [2], and the incidence of brain metastasis is $6.3-22.5 \%$ [3]. Metastatic lesions in the cerebral hemisphere and sellar area are rare and difficult to distinguish by imaging from more common sellar area tumors such as tuberculum sella meningiomas and large invasive pituitary adenomas. Here we report one case of chorionic carcinoma brain metastasis to the sellar area and summarize the recent literature.

\section{Methods}

One case of choriocarcinoma sellar region metastasis was analyzed, utilizing clinical data, MRI and

* Correspondence: huangyl13606903701@163.com

Neurosurgery Department of Zhongshan Hospital affiliated with Xiamen University, Xiamen, China pathological examinations, and clinical characteristics were summarized.

\section{Results}

Choriocarcinoma sellar region metastasis is easily misdiagnosed. We examined the literature and original resources to summarize the clinical characteristics of choriocarcinoma sellar region metastasis and discuss available therapies.

\section{Case presentation}

History: A 24 year old female was admitted into the gynecology department with a history of menopause and vaginal bleeding in the preceding two months and abdominal pain for one day. Her last menstrual period was four months prior and abnormal vaginal bleeding had occurred twice in the most recent three months. During hospitalization, the patient reported headaches and blurred vision. Upon physical examination, the patient was $165 \mathrm{~cm}$ in height and weighed $45 \mathrm{~kg}$. Blood pressure was 100/68 mmHg, pulse 58 beats/min. The patient reported loss of binocular eyesight acuity, bilateral temporal hemianopsia, left abdominal tenderness and painful bounce. Laboratory data are shown in Table 1. In particular, prolactin (PRL) and blood $\beta$-human chorionic gonadotropin

\section{Biomed Central}

() 2015 Sun and Huang. Open Access This article is distributed under the terms of the Creative Commons Attribution 4.0 International License (http://creativecommons.org/licenses/by/4.0/, which permits unrestricted use, distribution, and reproduction in any medium, provided you give appropriate credit to the original author(s) and the source, provide a link to the Creative Commons license, and indicate if changes were made. The Creative Commons Public Domain Dedication waiver (http://creativecommons.org/publicdomain/zero/1.0/) applies to the data made available in this article, unless otherwise stated. 
Table 1 Patient laboratory data

\begin{tabular}{|c|c|c|c|c|c|}
\hline \multicolumn{2}{|l|}{ Parameter } & \multirow{2}{*}{$\frac{\text { Laboratory data }}{2.17}$} & \multirow{2}{*}{$\begin{array}{l}\text { Normal range } \\
3.10-6.80\end{array}$} & \multicolumn{2}{|l|}{ Unit } \\
\hline FT3 & & & & $\mathrm{pmol} / \mathrm{L}$ & \\
\hline FT4 & & 7.23 & $12.00-22.00$ & $\mathrm{pmol} / \mathrm{L}$ & \\
\hline T3 & & 0.96 & $1.30-3.10$ & $\mathrm{nmol} / \mathrm{L}$ & \\
\hline T4 & & 55.24 & $66.00-181.00$ & $\mathrm{nmol} / \mathrm{L}$ & \\
\hline TSH & & 1.290 & $0.270-4.200$ & $\mathrm{mIU} / \mathrm{L}$ & \\
\hline$P R L$ & & 1806.00 & $102-496$ & $\mathrm{mlU} / \mathrm{l}$ & \\
\hline LH & & $<0.10$ & $2.4-12.6$ & $\mathrm{mlU} / \mathrm{l}$ & \\
\hline FSH & & 0.16 & $3.5-12.5$ & IU/I & \\
\hline $\mathrm{GH}$ & & 0.676 & $0.1260-9.8800$ & $\mathrm{ng} / \mathrm{ml}$ & \\
\hline ACTH & & 7.290 & $7.200-63.300$ & $\mathrm{pg} / \mathrm{ml}$ & \\
\hline PROG & & 0.45 & $0.6-4.7$ & $\mathrm{nmol} / \mathrm{l}$ & \\
\hline White blood cells & & 4.31 & $3.50-9.50$ & $10^{9} / \mathrm{L}$ & \\
\hline Red blood cells & & 3.42 & $3.80-5.10$ & $10^{12} / \mathrm{L}$ & \\
\hline Hemoglobin & & 102 & $115-150$ & $g / L$ & \\
\hline $\mathrm{Na}+$ & & 131.67 & $137-147$ & $\mathrm{mmol} / \mathrm{L}$ & \\
\hline K+ & & 3.52 & $3.50-5.30$ & $\mathrm{mmol} / \mathrm{L}$ & \\
\hline $\mathrm{Cl}$ & & 93.59 & $96.00-110.00$ & $\mathrm{mmol} / \mathrm{L}$ & \\
\hline Glucose & & 3.73 & $3.9-6.1$ & $\mathrm{mmol} / \mathrm{L}$ & \\
\hline U-SG & & 1.01 & $1.005-1.030$ & & \\
\hline$\beta-H C G$ & Pre-operation $15 d$ & Pre-operation $1 \mathrm{~d}$ & Post-operation 3d & Post-operation 30d & Post-operation 60d \\
\hline $\begin{array}{l}\text { Normal range } \\
(0-5.3 \mathrm{IU} / \mathrm{ml})\end{array}$ & 40636.0 & 499311.0 & 3957.0 & 56626.0 & 88729.0 \\
\hline
\end{tabular}

( $\beta$-HCG) were abnormally high. Preliminary diagnosis was either chorionic carcinoma or pituitary adenoma. Ultrasound (Fig. 1) examination showed pelvic cavity fluid accumulation and normal double ovaries. MRI shows diaphragma sella is pushed up, and sella bottom shows bone absorption and destruction. Diagnosis from MRI (Fig. 2) examination indicated possible pituitary adenoma.

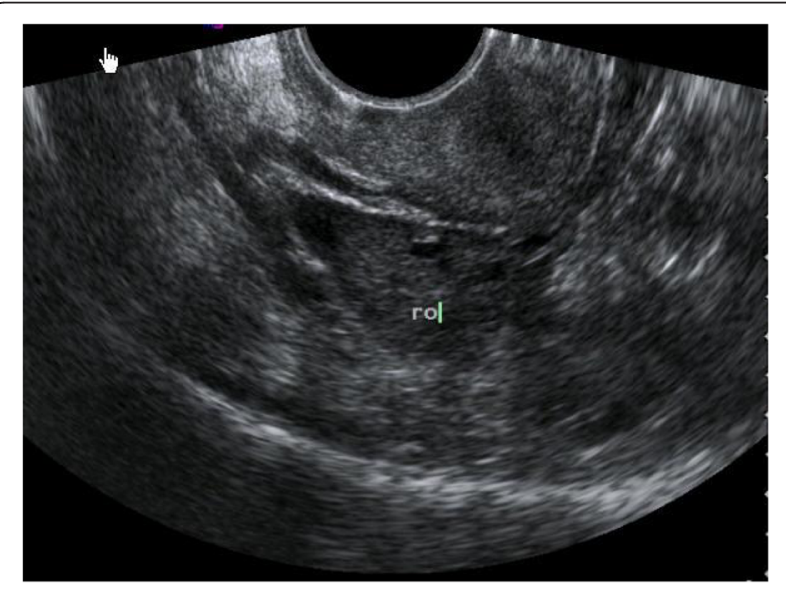

Fig. 1 Patient Ultrasound. Pelvic cavity fluid accumulation and normal double ovaries
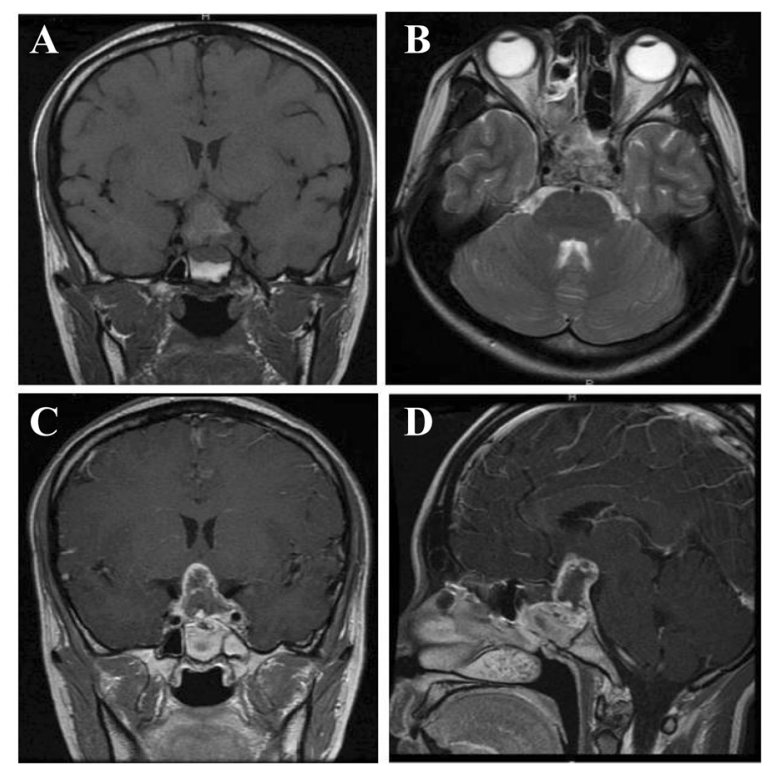

Fig. 2 Patient MRI. a, b MRI shows enlargement of the sella. Anteroposterior diameter is about $1.5 \mathrm{~cm}$, with mixed visible $T_{1} \mathrm{Wl}$ and $T_{2} W l$ signals in the sellar area. Scope is $2.5 \mathrm{~cm} \times 2.3 \mathrm{~cm} \times 2.0 \mathrm{~cm}$. c, $\mathbf{d}$ Enhanced mass is relatively low. Diaphragma sella is pushed up, and sella bottom shows bone absorption and destruction. Bilateral cavernous sinus boundary is not clear 
Physicians concluded that the serious decline in vision was the result of rapid sellar area tumor growth and transferred the patient to our neurosurgery department. Sella area tumor resection was performed by the supraorbital eyebrow keyhole approach. The bone flap was $3 \times 2 \mathrm{~cm}$. The frontal lobe was pull open to find a solid white tumor of tough disposition. The blood supply was extremely rich. The lesion was subtotally removed. The volume of the tumor resection was $2 \mathrm{~cm}^{3}$. The optic chiasm and optic nerve decompressed during the operation. Surgery proceeded smoothly and bilateral vision improved after operation but declined again after one month. An MRI scan verified tumor recurrence and the blood $\beta$-HCG level again increased. HE stain showed obviously regression abnormity tumor cells and immunostain revealed HCG expression in tumor cells. Pathological diagnosis was chorionic epithelioma (Fig. 3).

\section{Discussion}

Germ cell tumors account for $0.2-1.7 \%$ of intracranial tumors. Six subtypes of tumor have been described, including chorionic carcinoma, embryonal carcinoma and mixed germ cell tumors [3]. The most common germ cell tumors often occur in the pineal gland area (35.3\%) and sellar area (17.6 \%) [4]. However, chorionic carcinoma cerebral metastases are rare, particularly in the sellar region. Two cases of chorionic carcinoma metastasis to the sellar area were found in two references through the Embase system. One case was reported by Huashan hospital [5], the other was reported by Liu in Taiwan [6]. Both cases involved children. To our

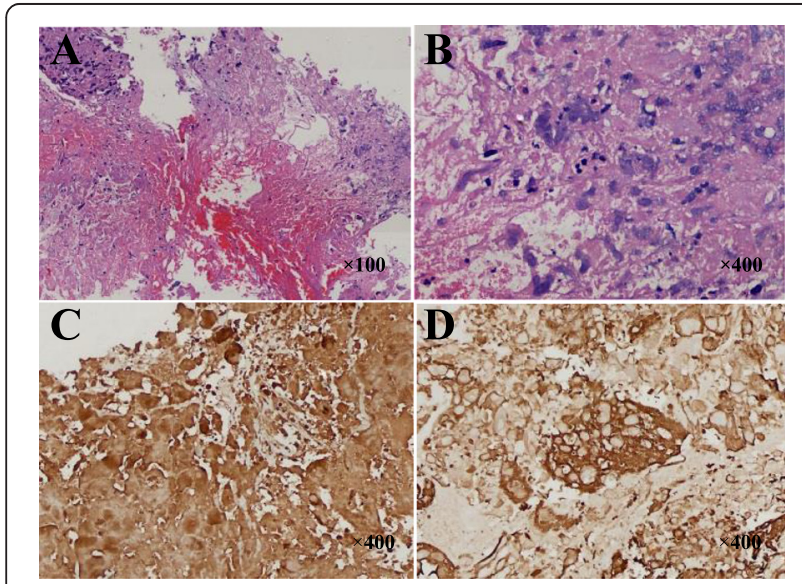

Fig. 3 Pathology of sellar region. a HE stain $(\times 100)$ shows large area of necrosis with a few variant cells. $\mathbf{b}$ HE stain $(\times 400)$ obviously regression abnormity tumor cells. c HCG immunostain $(\times 400)$ showing HCG expression in tumor cells. d CK immunostain ( $\times 400)$ showing CK expression in tumor cells. Immunohistochemical analysis: CK-P(+), PLAP(-), HCG(+), AFP(-) CD30(-), CD3(focal+), CD20(Individual cells + ), Vimentin(-), Syn(-), CgA(-), GFAP(-), CD117(-), PRL(-), GH(-), $\mathrm{ACTH}(-), \mathrm{LH}(-), \mathrm{FSH}(-), \mathrm{TSH}(-)$; Ki-67 positive cells: $35 \%$ knowledge, our report is the first case of chorionic carcinoma brain metastasis in a woman of childbearing age.

The patient in the present case had no previous history of pregnancy, but did report abnormal vaginal bleeding on two occasions before admission. Diagnosis was missed because no primary lesions were detected in ultrasound. Kyritsis et al. [7] reviewed cases of unknown primary brain metastases which included a few examples of chorionic carcinoma, based on imaging features of brain metastatic tumors, clinical manifestations or diagnosis of malignant brain tumor by biopsy. However, in these cases, the primary site of metastasis was not determined from patient history, physical examination or laboratory testing, and chorionic carcinoma accounted for only $3-5 \%$ of solid tumors.

The clinical characteristics of choriocarcinoma metastasis to the sellar area are summarized as follows: 1. History of sexual activity in women of childbearing age and recent irregular vaginal bleeding; 2 . Increasing urine output and aggravation of hyponatremia; 3. History of visual impairment and symptoms of high cranial pressure; 4. Endocrine disorders, pituitary function impairment, growth hormone deficiency and sexual developmental disorders; 5. Continuing increase in $\beta$-HCG after gynecological operation. Higher $\beta$-HCG levels can promote chorionic epithelial carcinomas or mixed germ cell tumors. Levels of $\beta$-HCG $>1000 \mathrm{mIU} / \mathrm{ml}$ (normal range $0-5.3 \mathrm{IU} / \mathrm{ml}$ ) are almost always associated with chorionic carcinoma or choriocarcinomic cell types in mixed germ cell tumors; 6 . Intracranial germ cell tumors easily metastasize through cerebrospinal fluid. Tumor cells can be detected in the cerebrospinal fluid of some patients, which is of great diagnostic significance, although the clinical detection rate is low. CT scan of chorionic carcinoma shows slightly higher density shadows accompanied by calcification and bleeding; 7 . Slightly higher or mixed signals in MRI $\mathrm{T}_{1} \mathrm{~W}_{1}$ scans occur because of different subacute periods of bleeding in the tumor;8. Microscopic pathological examination shows areas of poorly differentiated trophoblastic cells, hemorrhage and necrosis. Chorionic carcinoma can be definitely diagnosed if no villi structure is found with an accuracy rate of $70-80 \%$.

Chemotherapy is currently the preferred treatment for chorionic carcinoma. Radiotherapy and surgery may be used as complementary treatments. Surgery for brain metastases must be determined according to the situation. Minimally invasive surgery in the sellar area is feasible by nasal butterfly. A clear diagnosis from a pathological examination of intraoperative biopsy tissue must be obtained before deciding upon treatment methods. Chorionic carcinoma is a malignant tumor which occurs in the gonads and contains Sertoli cell components sensitive to chemotherapy. Unfortunately, because of the blood brain barrier, it is difficult to achieve concentrations of 
chemotherapeutic agents in the brain from systemic chemotherapy which are sufficient to suppress tumor growth. Therefore, radiotherapy using whole brain irradiation should be combined with chemotherapy. Radiation therapy is effective in most of cases and can significantly increase survival time.

\section{Conclusion}

Chorionic carcinoma metastases to the sellar area are not detected in early age. Disease progression produces vision loss and reduced pituitary function, and often results in serious nerve dysfunction because of misdiagnosis. This review and case study have been written to summarize our current understanding of the incidence and clinical characteristics of chorionic carcinoma metastases to the sellar area, and will hopefully give impetus to further study this serious disease.

\section{Abbreviations}

MRI: Magnetic Resonance Imaging; $\mathrm{FT}_{3}$ : Free triiodothyronine; $\mathrm{FT}_{4}$ : Free thyroxine; $T_{3}$ : Triiodothyronine; $T_{4}$ : Thyroxine; TSH: Thyroid-stimulating hormone; PRL: Prolactin; LH: Luteinizing hormone; FSH: Follicle-stimulating hormone; GH: Growth hormone; ACTH: Adrenocorticotropin; PROG: Progesterone; SG: Specific gravity of urine; HCG: Human chorionic gonadotropin; CT: Computed tomography; HE: Hematoxylin and eosin stain; CK: Creatine kinase.

\section{Competing interests}

The authors declare that they have no competing interests.

\section{Authors' contributions}

JS carried out the molecular genetic studies and clinical research, participated in the drafted the manuscript. YH conceived the study, participated in its design and coordination, and helped draft the manuscript. Both authors have read and approved the final manuscript.

\section{Acknowledgements}

We thank Dr. Tian Xinhua for helpful comments and suggestions.

Received: 3 June 2015 Accepted: 2 October 2015

Published online: 18 November 2015

\section{References}

1. Tabouret E, Bauchet L, Carpentier AF. Brain metastases epidemiology and biology. Bull Cancer. 2013;100(1):57-62.

2. Sievers $E L$, Berger $M$, Geyer JR. Long-term survival of a patient with primary sellar choriocarcinoma with pulmonary metastases: a case report. Med Pediatr Oncol. 1996;26(4):293-5.

3. Johnson $\mathrm{RH}$, Chien $\mathrm{FL}$, Bleyer $\mathrm{A}$. Incidence of breast cancer with distant involvement among women in the United States, 1976 to 2009. JAMA. 2013;309(8):800-5.

4. Gao Y, Jiang J, Liu Q. Clinicopathological and immunohistochemical features of primary central nervous system germ cell tumors: a 24-years experience. Int J Clin Exp Pathol. 2014;7(10):6965-72.

5. Chen L, Zou X, Wang Y, Mao Y, Zhou L. Central nervous system tumors: a single center pathology review of 34,140 cases over 60 years. BMC Clinical Pathology. 2013;13:14.

6. Ho DM, Liu HC. Primary intracranial germ cell tumor. Pathologic study of 51 patients. Cancer. 1992;70(6):1577-84.

7. Kyritsis AP, Markoula S, Levin VA. A systematic approach to the management of patients with brain metastases of known or unknown primary site. Cancer Chemother Pharmacol. 2012;69(1):1-13.

\section{Submit your next manuscript to BioMed Central and take full advantage of:}

- Convenient online submission

- Thorough peer review

- No space constraints or color figure charges

- Immediate publication on acceptance

- Inclusion in PubMed, CAS, Scopus and Google Scholar

- Research which is freely available for redistribution 